\title{
STUDY OF FEMALE STUDENTS RESILIENCE
}

\author{
P. Petkov ${ }^{*}$, M. Shoshev ${ }^{2}$ \\ ${ }^{1}$ Department of Physical Education and Sport, Trakia University, Stara Zagora, Bulgaria \\ ${ }^{2}$ Department of Social Activities, Faculty of Medicine, Trakia University, Stara Zagora, Bulgaria
}

\begin{abstract}
Resilience as a primary physical characteristic is determined by the fact that it allows characterization of the health of the younger generation. It determines the efficient operation of vital human body systems: cardiovascular, respiratory, circulatory system, musculoskeletal system and the aerobic metabolism of the organism. The aim of this study is to determine the level of physical performance of female students from Trakia University. Testing is applied as an assessment method of the level of endurance of 67 female students from the Faculty of Economics, Faculty of Agriculture and the Faculty of Veterinary Medicine, Trakia University, Stara Zagora, Bulgaria. Two tests are selected the Cooper and Beep tests. It is established that a very large relative part of the female students are characterized with unsatisfactory level of physical stamina development. Targeted and perennial work for the development of physical stamina, as well as a need for the intensification of the students to develop this characteristic during physical education classes are recommended. Convincing them that the level of physical endurance is directly related to health and the level of efficiency is significant.
\end{abstract}

Key words: Cooper test, Beep test

\section{INRODUCTION}

In the last few decades, we have witnessed the extremely negative tendency to reduce the motor activity of humanity and, in particular, of young people. The technical revolution and the rapid development of technology affect the quality of life. The tendency of poor nutrition and lack of physical activity is constantly increasing. Many scientific publications address the issue of reconsideration and correction of the physical workloads of adolescents and students, taking into account the results from the latest scientific studies on their physical status. The data are indisputable and indicate a decrease in human activity.

The lifestyle of modern young people is subordinate to the technological progress. Everyday life becomes more passive with regard to motor activity, resulting in increased hypodynamics and morbidity. The underestimation of individual needs of physical activity leads to many negative consequences - hypokinesia, overweight, emotional frustration, etc. (1).

\footnotetext{
*Correspondence to: P. Petkov, Department of Physical Education and Sport, Trakia University, Trakia University, Students Campus, 6000 Stara Zagora, Bulgaria, E-mail: jo_team@abv.bg
}

The physical capability of a person and the issues related to it have been exciting for generations. Endurance as a basic physical quality is determined by the fact that it characterizes the health of the younger generation. Exploring and studying the regularity of physical development, as well as the endurance status and progress will support the improvement of physical resistance and increase human performance. One of the first definitions of endurance is given by Farfel (1960) (2). In his work, he defined stamina as a property of the body to maintain its working capacity by overcoming the onset of fatigue, and later as an ability to practice the activity despite the fatigue onset. Later, similar definitions were given by Zatziorski (1966) (3), Zimkin (1968) (4), Lazarov (1976) (5), Zhelyazkov (1998) (6), Jeliazkov and Dasheva (2006), Yonov et al. (2005) (8), etc., who considered endurance as the ability to continuously perform any work without reducing its effectiveness.

A number of studies with students on the influence of various motor activities on the physical qualities and in particular on the endurance have been conducted (9-12). Contemporary scientific research in the field of sport shows that there are serious limitations in 
order to improve resilience in terms of the factors and mechanisms of energy exchange and vegetative systems. There are also many limits regarding the emergence of endurance quality at the psychological level - volition, process resistance and motivation.

The aim of the present study was to determine the level of physical performance of female students from Trakia University. To accomplish the goal the following tasks were set: (i) to perform literature survey of the problem; (ii) to develop a test battery and (iii) to process and analyze the test data.

\section{METHODS}

\section{Testing method}

The testing was conducted during the winter semester of the academic 2016/2017 year. The survey was comprised of 67 students from the Faculty of Agriculture, Faculty of Veterinary Medicine and Faculty of Economics, Trakia University, Stara Zagora, Bulgaria.

The testing battery included the following tests:

\section{The Cooper test}

The purpose of the test is to run a maximum distance within 12 minutes. Its results give an assessment of the physical condition of the tested person. The possible results are grouped into the following levels: Excellent, Very Good, Good, Satisfactory, and Unsatisfactory, and depend on the age and gender. Before the start, the athlete warms up appropriately, then:

- The athlete runs/walks along the route for 12 minutes.

- The assistant records the achievement with accuracy to the nearby check mark of 100 m.

- During the test it is intended to run as long distance as possible within 12 minutes.

- The test is designed to measure the physical condition, so running should be at a moderate pace instead of making sprints. The results are based on the distance travelled, as well as on the age and sex of the tested person.

\section{The Beep test}

A $20 \mathrm{~m}$ long track marked with two lines at both ends is measured. The study is conducted with an audio recording where the test is recorded. The tested athlete is behind the starting line, and after a beep (from the record), he/she starts the 20-meter track. When he/she hears a signal from the record, the athlete turns and runs the track in the opposite direction. The tested student should strive to maintain such a rate that between two signals he/she has run the distance of $20 \mathrm{~m}$, and at the sound signal the athlete only reverses the running direction.

After each passing minute, the intervals between the alerts become shorter, which requires the speed of the run to be increased. Each minute represents the corresponding level, and for passing to the next level there is a signal and a warning that the corresponding level ends and a higher one follows. The record contains 21 levels. The speed at the beginning of the test is very slow. The tested student must step at least with one foot behind the marker line. If he/she has arrived before the direction reversal signal, the athlete waits for the signal before inversing the running direction. If the set tempo is not adhered, it is given the chance to compensate the delay for 2-3 route lengths, then the tested one is removed and the last level reached is respected.

\section{Mathematical methods of analysis RESULTS AND DISCUSSION}

After the Cooper test, the female students showed the following results - the average run distance was $1352.24 \mathrm{~m}$. By comparison, the students from Sofia University "Kliment Ohridski" ran an average of $1.814 \mathrm{~m}$. Using the table for determination of the endurance level in 20-29 year old women, we found the following: $77.61 \%$ of the students surveyed had unsatisfactory levels of endurance, $14.93 \%$ had a satisfactory level, $4.48 \%$ were good, 98\% have shown a very good level and $0 \%$ have an "Excellent" endurance level. The results are plotted in Figure 1.

According to the results from the test, the endurance of the students from Trakia University was very weak. The unsatisfactory score was very high $(77.61 \%)$, and the excellent rating was zero. If we compare the students from Trakia University, NSA "Vassil Levski "and Angel Kanchev University of Ruse, the difference in the endurance levels between them is obvious (13). The students from NSA showed the following results unsatisfactory and satisfactory level showed $0 \%$, good level $-9.1 \%, 30.3 \%$ showed very good level and $60.5 \%$ had excellent level. The results obtained after the Cooper test by the students from the University of Ruse are as follows: unsatisfactory $30.8 \%$, satisfactory $50 \%$, good $15.8 \%$, very good $0 \%$ and excellent level $3.8 \%$. Graphically, these results are depicted in Figure 2. 


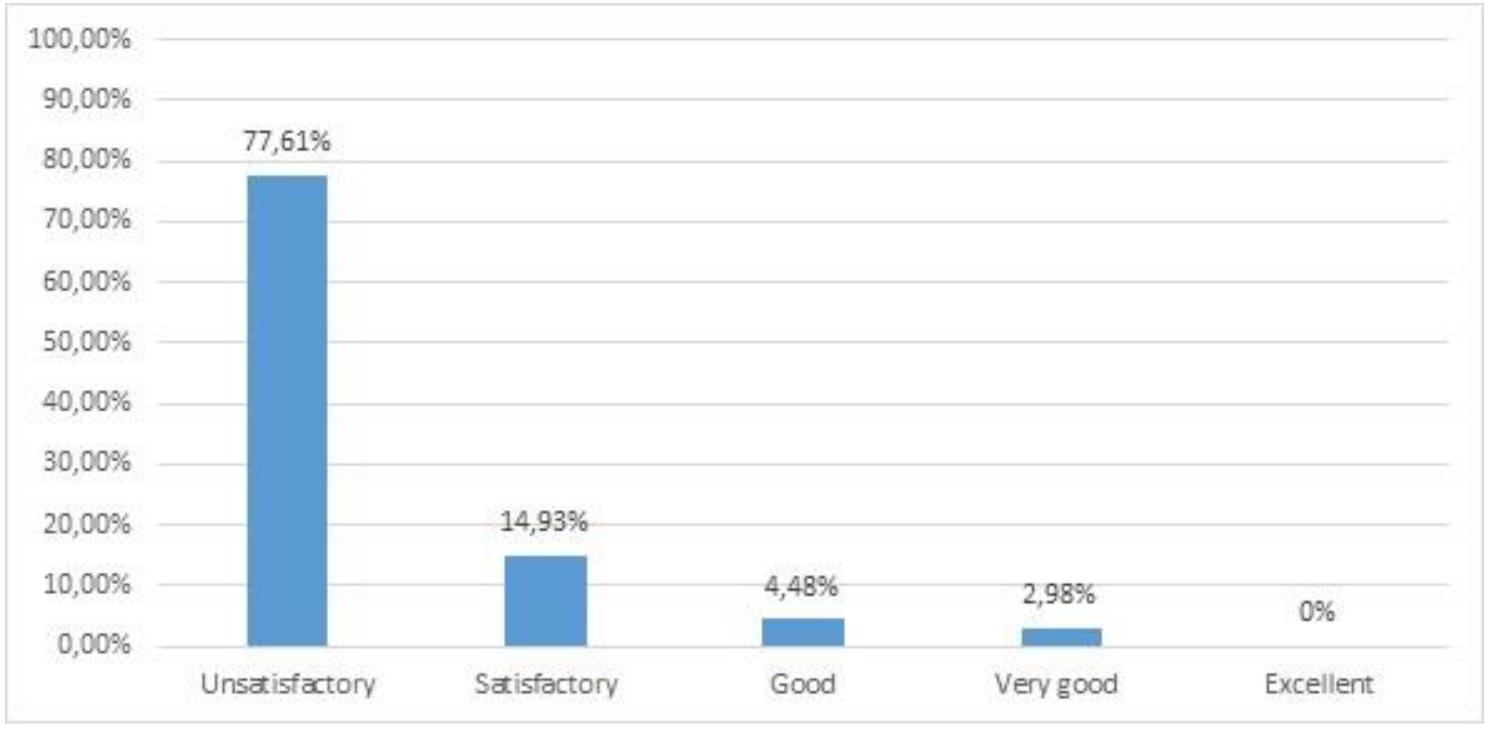

Figure 1. Results from the Cooper test.

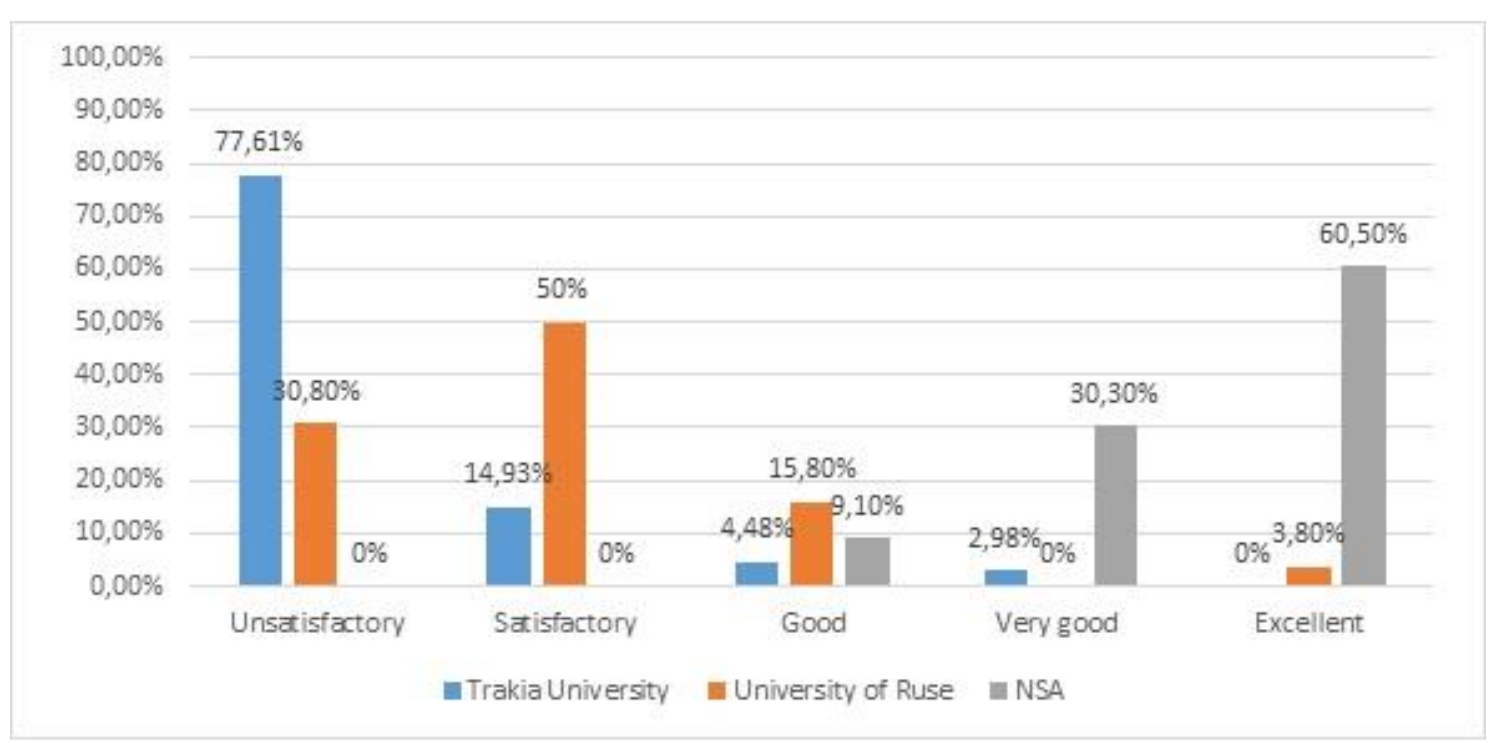

Figure 2. Comparison of the results from the Cooper test.

As expected the students from NSA had the best endurance, which is a function of the specifics of the university. They were followed by those from the University of Ruse and, last but not least, the students from Trakia University were the least resistant.
According to the Beep Test, there are 21 levels of workload, and depending on the level to which the tested students withstand, the level of their endurance is determined. Table 1 shows the levels according to the achieved results.

Table 1. Endurance levels of the Beep test.

\begin{tabular}{|l|c|c|}
\hline & Men & Women \\
\hline Excellent & $>13$ & $>12$ \\
\hline Very good & $11-13$ & $10-12$ \\
\hline Well & $9-11$ & $8-10$ \\
\hline Average & $7-9$ & $6-8$ \\
\hline Bad & $5-7$ & $4-6$ \\
\hline Very bad & $<5$ & $<4$ \\
\hline
\end{tabular}

The students tested from Trakia University achieved the following levels of loading $80.60 \%$ reached $2^{\text {nd }}$ level, $7.46 \%-3^{\text {rd }}$ level, $11.4 \%-4^{\text {th }}$ level. Nether of the students reached the fifth and thye subsequent load levels. According to these levels we have determined the levels of endurance. 88,06\% were at the "Very Poor" level, 11,94\% achievd "Poor" level, and at the higher levels of endurance there were no students. The graphical results are shown in Figure 3. 
PETKOV P., et al.

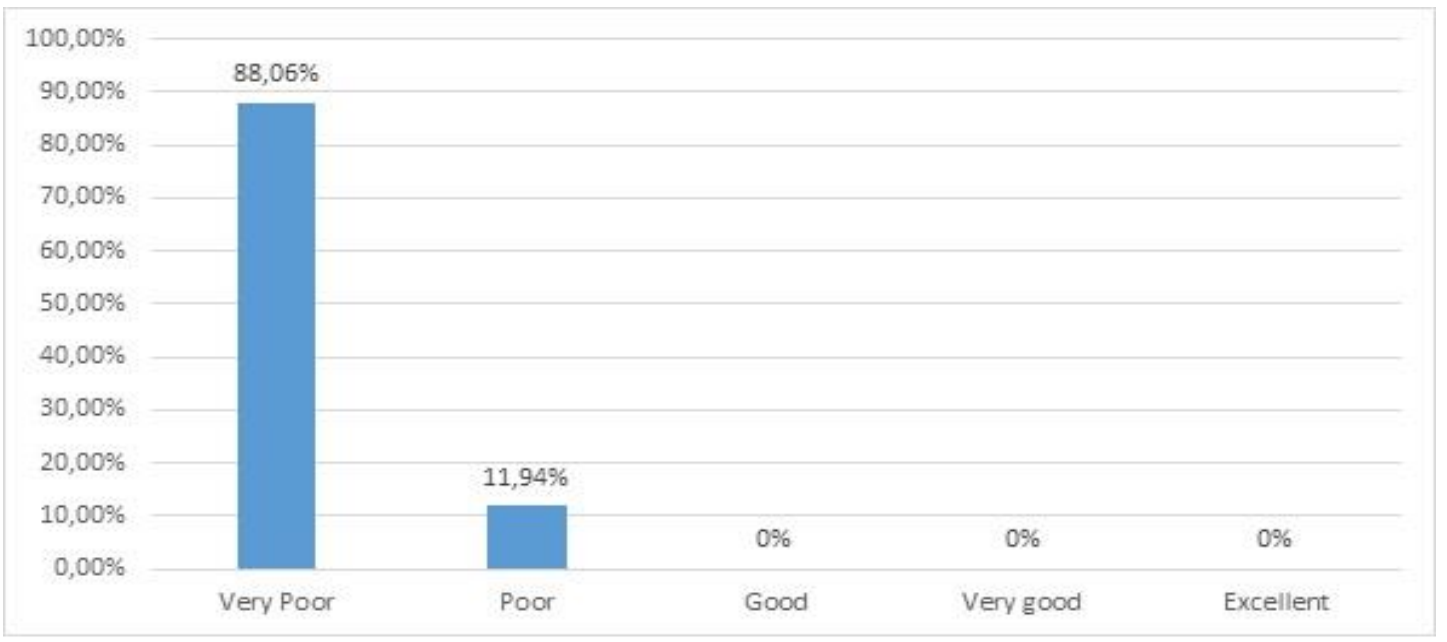

Figure 3. Results from the Beep test.

The average workload level of the students from Trakia University is 2.31. For comparison used the results obtained from the same test conducted in 2015 with students from Sofia University "Kliment Ohridski". They showed an average load level of 3.81. In this test, the students from Trakia University showed insignificant endurance. The lack of good, very good and excellent level is a very bad indicator of the development of this physical quality of the tested students.

\section{CONCLUSIONS}

The results of the present study outlined the following conclusions:

1. A very large proportion of the tested students had an unsatisfactory level of physical activity endurance.

2. A lack of moral qualities (stubbornness and will) to overcome fatigue and achieve better results was registered.

Thus, the subsequent recommendations are generated:

1. Purposeful and year-round work to develop physical endurance quality is needed.

2. Mobilization of students to develop endurance quality in Physical Education is necessary.

3. Convincing the students that the level of physical endurance is directly related to health and working capacity is significant.

\section{REFERENCES}

1. Karparova, I. Study on a model of students' endurance development by means of athletics, PhD Thesis, Sofia, 2015. (in Bulgarian)

2. Farfel, V.S. Sports physiology surveys, Fiscultura $i$ Sport, Moscow, 1960. (in Russian)

3. Zatziorski, V.M. Physical qualities of the athlete, Fiscultura i Sport, Moscow, 1966. (in Russian)

4. Zimkin, N.V. The significance of the activity for improving the function of the human body and modern society, Fiscultura $i$ Sport, Moscow, 1968. (in Russian)

5. Lazarov, G., Development of the basic physical qualities in average runs, Sofia, 1984. (in Bulgarian)

6. Zhelyazkov, Tzv. Basics of Sports Training, Sofia, 1998. (in Bulgarian)

7. Zhelyazkov, Tzv. and Dasheva, D. Basics of Sports Training, Sofia, 2006. (in Bulgarian)

8. Yonov, I., Bonov, P., et al. Track-and-Field Athletics in School, Sofia, 2005. (in Bulgarian)

9. Peeva, P. and Dyakova, G. Effect of the training program Cardiocallanetics on some morphofunctional characteristics of female students. $4^{\text {th }}$ International Scientific Congress Sport, Stress, Adaptation, ISBN 978-954-723006-4: 614-617, 2006.

10.Dyakova, G., Peeva, P. and Bozhkova, A. Influence of the PG FITNES program on the physical fitness of female students. $12^{\text {th }}$ European Congress of Sport Psychology, Sport and Exercise Psychology Bridges Between Disciplines and Cultures, Halkidiki, Greece, Book of Long Papers, ISBN: 978960-89923-0-6, 021:310-312, 2007.

11. Dyakova, G. Examination of the dependence between reduced physical activity - physical qualities and morpho-functional indicators of students, Sport \& Science, ISSN 1310-3303, C, 1:116-121, 2008. (in Bulgarian)

12. Dyakova, G. Effect of Body-programme on physical qualities and morpho-functional indices of female students. Sport \& Science, ISNN 1310-3393, Extra issue, Proceeding book, XVI ISC “Olympic Sport and Sport for all” \& VI ISC “Sport, Stress, Adaptation”, 52256, 2012.

13. Popova, S., Obreshkov, D. and Grigorova, M., Comparative analysis of the physical resilience of students from NSA "Vassil Levski" and Angel Kanchev University of Ruse, Proceedings University of Ruse, 49(8.2): 55-58, 2010 (in Bulgarian) 